REVIEW ARTICLE

\title{
Investigation of Unnatural Death
}

\author{
*A Barek ${ }^{1}$, SMT Haque ${ }^{2}$ \\ ${ }^{1}$ Prof. Dr. Abdul Barek, Head, Department of Forensic Medicine \\ Anwer Khan Modern Medical College, Dhanmondi, Dhaka \\ ${ }^{2}$ Dr. Syed Md. Tanjilul Haque, Assistant Professor, Department of Forensic Medicine, \\ Anwer Khan Modern Medical College, Dhanmondi, Dhaka
}

*Corresponding Author

ABSTRACT

A complete systematic investigation of unnatural death helps the court hugely to give an acceptable judgement. Legal officers like officer-in-charge of a police station, magistrates, witnesses of death circumstances and the forensic pathologists are basically involved in such investigation. Proper and true documentation by investigating officer are necessary. Identification of the deceased person, cause of death, manner of death, mode and mechanism of death, time since death, weapons used to cause the injuries etc. are opined in the investigaiton report as per direction given in the code of criminal procedure. These matters have been discussed in this article.

Key Words: Investigating officer, police inquest, magistrate inquest, coroner inquest, medical examiner inquest, autopsy, forensic pathology.

\section{Introduction}

Human beings face death at the end of life. Death is the permanent and irreversible ceassation of the physiological functions of the most important organs of the body, viz, heart, lungs and brain. Many die of old age or a disease. This is known as natural death. Others may die due to accident or homicidal or suicidal actions. These unusual kinds of death are known as unnatural death. Some deaths, though natural i.e. due to illness or old age are so sudden or suspicious, that these need to be excluded from unnatural deaths. So, question of investigation comes in case of unnatural, sudden, suspicious or unexplained deaths. Investigaion of death is necessary to punish the offender by a criminal court, to pay compensation by the defendant party to the heirs of the deceased person and to remit the wrongly accused person in case of sudden and suspicious natural deaths. There are several systems of investigation of unnatural death, viz, police inquest, magistrate inquest, coroner inquest, medical examiner inquest etc.

\section{Discussion}

Formal or official investigation of somebody's death which is unnatural, sudden, suspicious or

unexplained by an authorized officer is known as inquest. ${ }^{1}$ It is a fact finding inquiry to determine the apparent cause of death and the circumstances which lead to the death of a person. Its purposes are to findout where, when and how a person came to be dead ${ }^{1}$ and some times to find out his identification. In other words the cause of death, mode and manner of death, time of death and other circumstances of death need to be found out to complete an inquest. Some examples of accidental circumstances are road traffic accident, being knocked by road vehicle or train, a fall from a tree, balcony, or building, electrocution, lightning, death due to accidental drowning, burns by accidental toppling of a bottle lamp. Hanging, self poisoning, shooting a person himself, death by cutting one's own neck, jumping infront of a train, jumping into a well, river or sea are some examples of suicidal circumstances. Deliberate killing of somebody else, i.e, homicidal circumstances are murder by stabbing, shooting, clubbing or cutting, deliberate poisoning of somebody, squeezing the neck of a person etc.

AKMMC J 2014; 5(2): 34-38 


\section{Certification of Natural Death}

Issuing death certificate without investigation: When a person dies in hospital or at home during the medical care of registered medical practitioners having been diagnosed with a natural illness which has resulted in death, the doctor can issue a death certificate and no further investigation is necessary. Here, the main cause of death and any underlying reason or precipitating factors may be included in the "cause of death" certificate ${ }^{2}$.

In Bangladesh, police inquest and magistrate inquest are in practice. In the UK, Srilanka and some states of USA medical examiner inquest is done.

\section{Police Inquest}

On receiving information regarding an unnatural death FIR (first information report) form is duly filled up and signed by the informant and the police officer of the police station and it is entered in criminal register (CR) marked with a case number.

As per S-174 of the code of criminal procedures, ${ }^{3,4} 1898$, Modified in 1995,

(1) The police officer of a police station or some other empowered police officer conducts an Inquest. On receiving the infromaiton that a person. (a) has committed suicide or (b) has been killed by another or by an animal or by machinery or by accident or (c) has died under circumstances raising a reasonable suspicion that some other person has committed an offence, he shall immediately give infromaiton thereof to the concerned magistrate and shall proceed to the place where the body of such deceased person is and there, in the presence of two or more respectable inhabitants of the neighbour hood, shall make an investigation and draw up a report of the apparent cause of death, describing such wounds, fractures, bruises and other marks of injury as may be found on the body and stating in what manner or by what weapon or instrument (if any) such marks appear to have been inflicted.

(2) The report shall be signed by such police officer and other persons, or by so many of them as concur therein and shall be forthwith forwarded to the chief metropolitan/judicial magistrate or the district magistrate.

(3) When there is any doubt regarding the cause of death or when, for any other reason, the police officer considers it expedient to do so, he shall, subject to the rules as the government may prescribe in this behalf, forward the body, with a view to its being examined, to the nearest civil surgeon or other qualified medical man (teachers of forensic medicine of Government Medical College) appointed in this behalf by the government.

As per S-175, (1) a police officer investigating such unnatural death can summon in writing two or more persons acquainted with the facts of the case, and every person, so summoned shall answer truly all questions.

\section{Magistrate Inquest}

As per S-176, (1) when any person dies while in the custody of the police, the nearest authorized executive magistrate will held inquiry into the cause of death either instead of or in addition to the investigaiton held by the police officer. This is called magistrate inquest.

(2)When such magistrate considers it expedient to make an investigation of the deadbody of any person who has been already interred, in order to discover the cause of death, the magistrate may cause the body to be disinterred (exhumed) and examined. For exhumation, the grave needs to be identified by relative of the deceased person and the responsible officer of the graveyard. Early morning is the traditional time for exhumation. Where poisoning is suspected, samples of soils and grave-water are taken from above, below and sides of the corpse, as well as a control sample from a distant part of the graveyard. Then the body is sent to the morgue. The same procdure is followed to get the body autopsied.

\section{Coroner Inquest}

The coroner, ${ }^{5}$ known since 1194 in the UK, is either a lawyer or a doctor employed by the city or county administration to inquire into certain types of death. The cases are reported to him by the police, the public, doctors, local registrar of deaths. He investigates the follwing types of death- 
1. Where the deceased was not attended in his last illness by a doctor.

2. Where the deceased was not seen by a doctor either after death or within 14 days prior to death.

3. Where the cause of death is unknown.

4. Where death appears to be due to industrial disease or poisoning.

5. Where death may have been unnatural or have been caused by violence or neglect or abortion or attended by suspicious circumstances.

6. Where death has occurred during surgical operation or before recovery from anaesthetic.

On receiving a report of death from a doctor the coroner can- 1.decide not to pursue further inquiry, requesting the doctor to issue a death certificate, Or 2.can direct a forensic pathologist to conduct an autopsy. If the result of autopsy reveals natural causes, the coroner can issue a death certificate to the family for the disposal of the body. Or 3.can conduct an inquest into the circumstances of death where, when, how the person died including autopsy by a forensic pathologist. He must not direct blame either of criminal or negligent nature to any person. That will be decided by court.

The coroner inquest must arrive at a verdict, which may be one of the following-

1. Unlawful killing, 2. Accident, 3. Suicide, 4. Natural cause, 5. Industrial disease, 6. Dependence on drugs or 7. Open verdict (meaning yet the evidence is insufficient to arrive at any definite conclusion).

\section{Medical Examiner Inquest}

In the USA, this system of inquest was introduced in 1877. It works under public health department and can work independently. It has been gradually developed to the present high quality investigating agent on unnatural death. The medical examiner ${ }^{6,15,16}$ is an experienced physician in the field of Forensic Pahtology. His office is adequately staffed, equipped with modern instruments, gets adequate funding from the government and enjoys adequate civil service protection. Under the law, violent deaths (accident, suicide, and homicide), suspicious death, sudden and unexpected death, death without a physician in attendance, death in jail and penal institutions fall under the medical examiner's jurisdiction. Death of any individual dying within 24 hours of admission to a hospital is also reported to the medical examiner for a check up. Scene of death is visited by the medial examiner for a detailed history and circumstancial findings. Medical records of the deceased person are also examined. Then he decides whether autopsy and other tests are to be performaed or not.

When the body is brought to his morgue, the medical examiner himself performs an external physical examination and some laboratory tests. Blood from subclavian vessels and vitreous from the eyes are taken if no autopsy is perfomed. If autopsy is performed, blood, vitreous, urine and bile are obtained for toxicological examination ${ }^{5}$. All body fluids are taken into glass tubes or bottles. If the body is decomposed, then liver, kidney and muscles are retained. When oral medications are suspected, stomach contents also is retained. All fluids and tissue removed for toxicological purposes are kept for 3-5 years.

Tissues are also retained for possible microscopic examination. In homicide cases, photographic documentation of the injuries are useful.

\section{Autopsy of the Deadbody}

The investigating officer (Police officer, magistrate, coroner or the medical examiner) examining the body at the scene where it was found makes a preliminary inquest report. $\mathrm{He}$ fills up a form (chalan ${ }^{2}$ or requisition form) for sending the corpse for autopsy as well. The dead body along with the copies of these two papers is sent to the morgue. In the morgue the forensic pathologist gets the body identifided by the escorting police constables and relatives, if any, of the deceased person. The forensic pathologist ${ }^{7,18,19,20}$ goes through the inquest report, chalan form and talks to the relatives to know when, where, how the person came to be dead. Past medical history of the dead person is also inquired. The forensic pathologist in his 
well equipped morgue firstly, examine the body externally for features like, height, health state, hairs, body orifices, eyes, any marks, post mortem body changes like hypostasis, rigor mortis, putrefactive changes. The clothes with the body are also examined for any changes. All injuries and marks seen externally are noted. Then the body is systematically dissected. All injuries and/or diseased conditions are noted. Any foreign body found within the body is preserved. Specimens ${ }^{15}$ like blood, urine, bile, stomach content, vitreous are collected for toxicological analysis. Tissue specimens from the liver, kidney, heart, lung, brain etc are collected for histopathological examination. The post mortam report form is filled up as soon as possible after completion of the autopsy. In the opinion column of the report, the cause, manner and time of death are opined along with a sentence regarding the mechanism of death. Sometimes, the cause or manner of death cannot be determined by autopsy due to putrefaction or postmortem burn. In addition, the forensic pathologist will make a death certificate stating the cause and date of death. This will be useful incases of persons who were in any service, had life insurance policy and whose properties will be inherited by others etc. Clinicians, lawyers and lay public often find difficulty to understand the difference between cause of death, mechanism of death and the manner of death.

Cause of death: It means any injury or disease that produces a physiological disarrangement in the body that results in the individual dying. Examples of cause of death ${ }^{8,17}$ are a gunshot wound of the head, a stab wound of the chest, adenocarcinoma of the lung, coronary atherosclerosis etc. The lesion is identified by gross examination and occasionally by histological examination. Sometimes body fluids are tested for any poison or chemical. Site of wound, extent of the injury, amount of haemorrhage, any infection etc. are also considered to determine the cause of death.

To remark as to the type of weapon, features of the wound, eversion or inversion of the margins, wheather clean cut or not, torn state or crushing of the edges, amount of bleeding, its dimensions etc. are considered.
Mechanism of death: Mechanism of death ${ }^{9}$ means a physiological derangement produced by the cause of death that results in death. Examples are heamorrhage, septiceamia, cardiac arrhythmia. A particular mechanism of death may be produced by multiple causes of death and viceversa. "cardiac arrest" or "cardiopulmonary arrest" is not the cause of death.

Manner of death: Manner of death ${ }^{10}$ explains how the cause of death came about. Manners of death are generally considered to be homicide, suicide, accident (these are unnatural) and the commonest is natural. Some manners of death may remain "undermined" as one is not sure to put it into above classes. Homicide means killing a human being by another, suicide means self killing and accident means death occured due to an unforseen and unexpected event and natural means death is due to a disease or old age. Another manner is rash or negligent death, death occurs due to hurried action or failure to take care by others. Sometimes a stress may precipitate a fatal cardiac arrhythmia in an apparently normal old person with ischemic heart disease. Manner of death is determined from the informations about the circumstances surrounding the death site and severerity of injuries, type of weapon used etc. Approximate time of death is determined on the basis of muscle flaccidity of the deceased, development of rigor mortis, rectal temperature, postmortem staining, stages of putrefaction, development of saponification and mummification.

Mode of death: Mode of death ${ }^{11,13}$ means what vital organ at first stops when a person dies. If the heart stops first, the mode of death is called syncope, if the lungs ceases to function, the codition is called asphyxia and if the brain ceases to function producing unconsciousness it is called coma. These are not causes or manner of death, but may be considered as a mechanism of death.

Somatic death or clinical death: Somatic death $^{1,12}$ means a person no longer functions as a unit of the society because he is irreversibly unconscious and can not communicate with the environment and is unaware of his own or the world's existence. There is complete and irreversible loss of functions of his brain, heart and lungs. It is noted that permanent loss of 
cerebral cortical functions with intact brain stem functions (breathing, blood circulation) is considered as vegetative state and not death. In so called apparent death or death trance, signs of life are interrupted or reduced to minimum for some time. Artificial life support and other emergency management may cause the person to survive.

When the investigating officer gets the autopsy report he incorporates this in his inquest report. He summerises the findings of the FIR, visit of scene of death, statement of the witnesses, autopsy report and gives a verdict whether it is a criminal case or not. If informations are insufficient he keeps it as open verdict i.e. the investigation is suspended and waits for further informations in future.

In homicidal and negligent ${ }^{14}$ cases, his all documents regarding the case are submitted to the criminal procecution service for further action in the court. Rash and negligent death cases are similarly dealt with. The complainant may bring a civil action for damages. Here he needs to prove the case showing that death was due to negligence of the defendant. In suicidal and accidental cases the investigation ends at the end of the inquiry about the death without any further reference.

\section{Conclusion}

If sincere and intelligent medicolegal investigation is carried out all systems will give a fruitful result. Medical examiner inquest system sounds better because forensically experienced doctor does the investigation from the beginning to the end and he has in-depth knowledge of death. To carry out an adequate autopsy the forensic pathologist in Bangladesh needs adequate forensic knowledge and skill mordern instruments and dedication. Each one should consult with his experienced collegues in complicated and pressurized cases.

\section{References}

1. Knight B, Medical aspects of death, In: Simpson's Forensic Medicine, $10^{\text {th }}$ Edn, Kent, Edward Arnold, P 12-27.

2. Barek A, Medicolegal system in Srilanka, My experience, Bangladesh Medical Review, vol 23, No.4, 1997, P 16-18

3. Nandy A, Legal procedures in medicolegal cases, In: Principles of Forensic Medicine, 2nd Edn, 2000, Calcutta, New Central Book Agency Ltd, P 3-13
4. Ministry of Law and Justice Government of the Peoples Republic of Bangladesh, The Code of criminal procedure, 1898, as modified upto 30th September, 1991, P 77-79.

5. Knight B, The Forensic autopsy, In: Forensic Pathology, 1st Edn, Edward Arnold, London, 1991, P 1-46

6. Maio DJD and Maio VJM, Medicolegal investigatives systems; In: Forensic pathology, Elsevier science publishing Co, N.Y, 1989, P 1-19

7. Islam AKMS, Barek A, Pattern of unnatural death, Bangladesh Medical Review, Vol 17, No.1, 1991, P 38-41.

8. Reddy KSN, Medicolegal autopsy, In: The Essentials of Forensic Medicine and Toxicology, 24th Edn 2005, Hyderabad, published by K Suguna Devi, P 84-109

9. Mallik CC, Death in its medicolegal aspects, In: A short Text Book of Medical Jurisprudence. 2nd Edn, The New Bookstall, Calcutta, 1984, P 124-180.

10. Sengupta K, Criminal procedure in India, In: Medical jurisprudence \& Toxicology, 1st Edn, 1978, Academic publishers P 3-16.

11. Knight B, The obscure autopsy, Foren Sci Int 1980; $16 ; 237-40$

12. McCurdy W; Postmortem specimen collection; Forensic Sci Int 1987; 35; 61-6

13. Segerberg M, Determination of cause and mode of death before and after medicolegal autopsy J Forensic Science 1988, 33, 441-7

14. Barek A, Death of 7 children due to organic carbamate poisoning, TAS journal of Teacher's Association vol 8, No.20, 1999, P 536-37

15. James FE: Deadly job-local coroners lack of forensic training raises issue of fitness, Wall streat journal, vol 82, No.118, December 16, 1988

16. Clark M, Application of clinical laboratory tests to the autopsy; a practical guide for specimens, Am J Forensic Med \& Pathol, 1981;2; 75-82

17. Lead beatters, Knight B, The history and the cause of death; Med sci law, 1987; 27, 132-35.

18. Cordner SM, The role of the second postmortem examination, Med leg J, 1985, 53, 24-8.

19. Ghanem I Permission for performing an autopsy: the pitfalls under Islamic law. Med Sci Law 1988, 28, 241-42

20. Tedeschi. Future of the autopsy; a determination. Am J Forensic Med pathol 1980; 1; 103-4 